\title{
THE EFFECT OF CYCLONE SURFACE AREA TOWARDS ENGINE PERFORMANCE, INTAKE MANIFOLD PRESSURE AND EXHAUST GAS EMISSION
}

\author{
SUGENG HADI SUSILO, NURHADI \\ Department Mechanical Engineering, State Polytechnic of Malang, Indonesia
}

\begin{abstract}
This paper discusses engine performance and exhaust emissions based on the surface area of the cyclone. It is used as an attachment to the air duct before the intake manifold. The research aims to improve the level of mixing air with fuel, thereby improving fuel combustion. The research object is engine performance, intake manifold pressure, and waste emissions. engine performance is analyzed based on engine power and torque, while exhaust emission analysis is based on $\mathrm{HC}$ and $\mathrm{CO} 2$ gases. The intake manifold diameter of $54 \mathrm{~mm}$ is the result of the length of the cyclone blade, and the width of the cyclone blade is determined by values of $10 \mathrm{~mm}, 20 \mathrm{~mm}$ and $30 \mathrm{~mm}$. The surface area of the cyclone blades is $810 \mathrm{~mm} 2,1620 \mathrm{~mm} 2$, and $2430 \mathrm{~mm}$. Then the cyclone is placed before the intake manifold, precisely at the throttle valve.

The results obtained affect when adding a cyclone with a blade surface area of $1620 \mathrm{~mm} 2$ of $87 \mathrm{Hp}$ at $5500 \mathrm{rpm}$ engine speed and the resulting torque value of $312 \mathrm{Nm}$ at $3500 \mathrm{rpm}$ engine speed with the resulting average effective pressure of $1049 \mathrm{kPa}$ or equivalent to 10 bar at $2500 \mathrm{rpm}$ engine speed. Furthermore, the power produced and the use of a cyclone only affects high engine speed because the air and fuel flow produced is higher than when the engine speed is low. However, when the engine speed is too high, the power produced is low due to the possibility of the intake valve closing before the air and fuel flow into the cylinder. In the data of torque and average effective pressure that is generated along with the high engine speed, the resulting value is also low because the friction coefficient of the piston movement is large and the degree of filling of the cylinder decreases, resulting in low torque and the resulting average effective pressure.
\end{abstract}

KEYWORDS: Engine Performance, Exhaust Emissions, Cyclone Surface Area, Intake Manifold Pressure

Received: Jun 08, 2020; Accepted: Jun 28, 2020; Published: Sep 17, 2020; Paper Id.: IJMPERDJUN20201307

\section{INTRODUCTION}

The cyclone is a device that functions to change the intake manifold airflow from laminar flow to turbulence flow. It is made of stainless steel. It is several fins with an inclination angle to the upright axis of this tool mounted on the air channel before the intake manifold. Its change in airflow is expected to improve the air mixing rate with the fuel [1]-[3]. It can happen because one of the factors of the chemical reaction process in the form of a reacting substance and the large surface area of the cyclone is expected to produce a more homogeneous mixture of air and fuel flow, improving the combustion process in motor vehicles. The combustion process will be perfect if there is enough air so that all carbon elements become carbon dioxide and all hydrogen elements become water, but the combustion process takes place imperfectly in the presence of elements $\mathrm{C}, \mathrm{H} 2, \mathrm{CO}, \mathrm{HC}$ emissions of exhaust gas [4]-[7]. Cyclone is made of stainless steel, which has several fins at an angle to the vertical axis. It is installed in the airways before the intake manifold or before the throttle valve. Rotating airflow is expected to improve fuel-air 
mixing [8]-[10]. [11]-[13] state of the cyclone used on a combustion motor functions to make the airflow in the Intake Manifold rotates, thereby improving fuel and air mixing.

[14] state of the use of cyclone can reduce the intake pressure manifold drop. The flow of air that flows through the cyclone, the pressure drops, and the air goes into the combustion chamber. If the engine is still using a carburetor system, The ignition of the fuel is in the middle of the flow, causing the fuel and air to become homogeneous. The flow of air and fuel is very fast flowing resulting in the fuel not sticking to the combustion wall, and this happens when the engine accelerates-continuous turbulent airflow in the process of combustion of airflow to the exhaust manifold-thereby causing the flame to spread evenly. The fuel-burning completely, preventing the engine from vibrating, preventing vibrations and abrasion, and extending engine life.

[15]-[18] concluded that the cyclone's dimensions are essential because they affect the performance of the airflow entering the engine and influence the drop pressure. [19]-[22] state of the use of turbo cyclone with blades without holes can increase the inlet and outlet sides and the intensity of turbulence, this is proportional to the increase in pressure drop. [23]-[25] concluded that the air turbulence model of the intake manifold influences engine performance. It affects the filling of air in the combustion chamber, thermal efficiency, and combustion quality.

[26] conclude that cyclone testing with a $120 \mathrm{~mm}$ diameter has a right level of turbulence, high-pressure drop resulting in cyclone performance at different gas concentrations. [27], [28] concluded that cyclone with a specific diameter could increase the kinetic energy of airflow in the combustion chamber. The flat bottom shape of the swirl generator produces good aerodynamic levels and can change the pressure and speed of the air entering the intake and form a more homogeneous airflow. [29] uses three types of swirl generators that are symmetrical, concave, and flat. It aims to determine the effect of airflow on swirl generators using angles of $0^{\circ}, 5^{\circ}$, and $10^{\circ}$. The result of using a swirl generator with an angle of $10^{\circ}$ can inhibit the flow of air into the combustion chamber[4], [30]. Whereas the use of swirl generators affects torque, this increases with the throttle opening. It shows that the combustion process using a swirl generator affects the fuel period, the combustion rate, and the period of combustion. High turbulent airflow can increase the combustion period [31].

\section{MATERIAL AND METHOD}

\subsection{Object of Study}

The purpose of the study is performance engine, intake manifold pressure, and exhaust gas emissions. Engine performance is analyzed based on engine power and torque, while exhaust gas emission analysis is based on $\mathrm{HC}$ and $\mathrm{CO} 2$ gases. The Cyclone Design. Cyclone to be designed, as shown in Figure 1. 


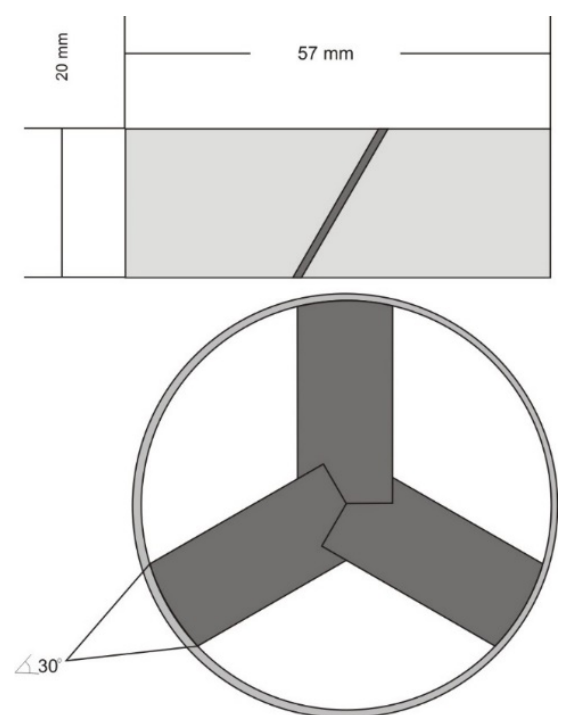

Figure 1: Cyclone Design.

Intake manifold diameter of $54 \mathrm{~mm}$ is the result of the length of the cyclone blade, and the width of the cyclone blade is determined by values of $10 \mathrm{~mm}, 20 \mathrm{~mm}$ and $30 \mathrm{~mm}$. It is using cyclone blade surface area $810 \mathrm{~mm} 2,1620 \mathrm{~mm} 2$, and $2430 \mathrm{~mm} 2$. Then the cyclone is placed before the intake manifold precisely on the throttle valve, more clearly as in the sketch below:

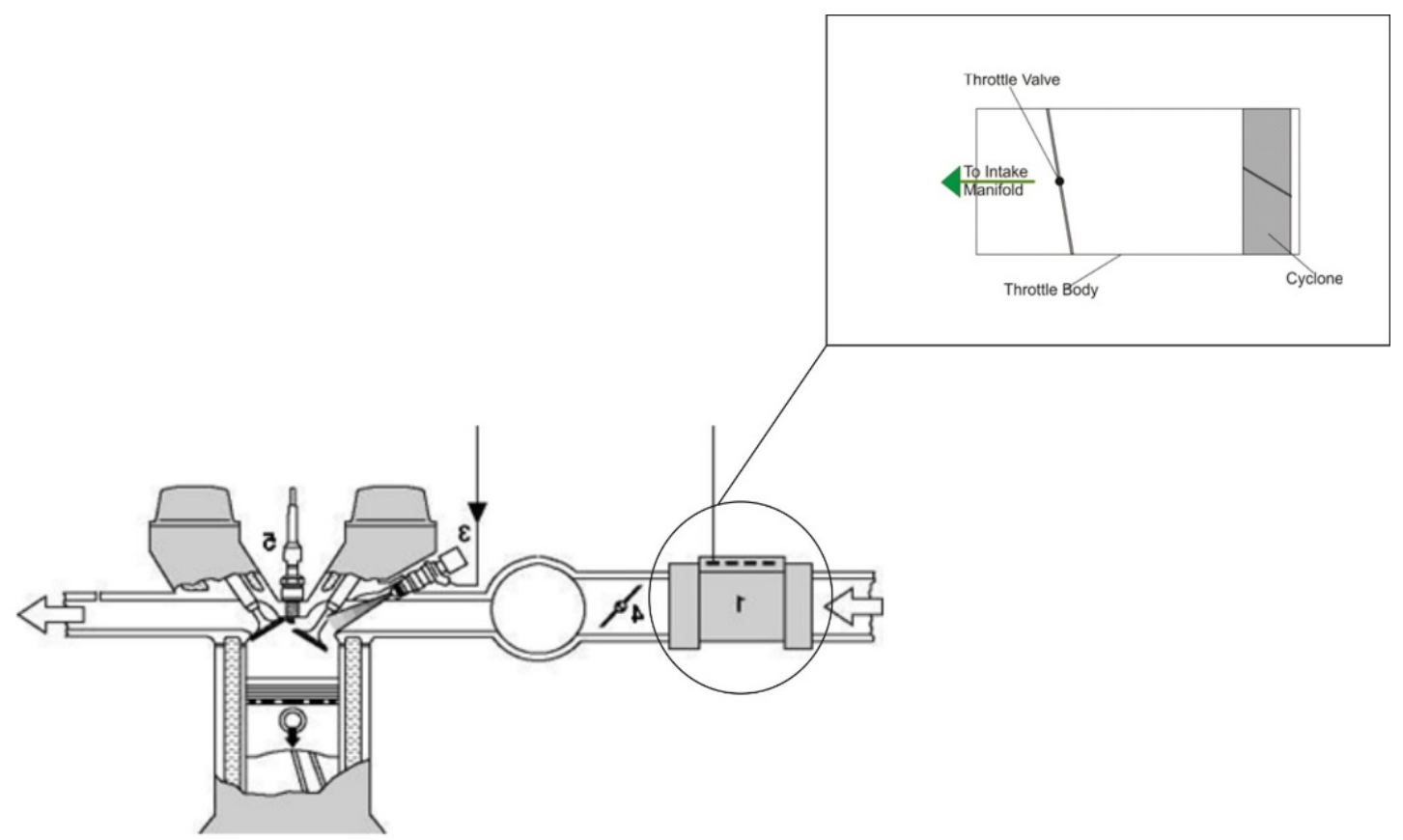

Figure 2: Cyclone Mount Position. 


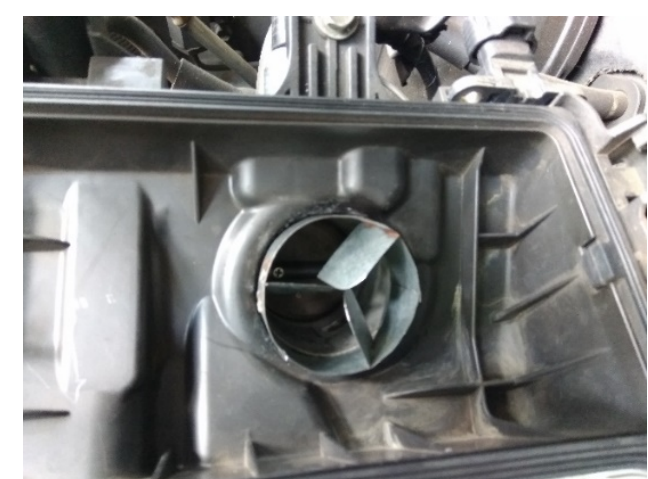

Figure 3: Position of Cyclone Mounting on Intake Manifold

The manifold diameter of $54 \mathrm{~mm}$ is the result of the length of the cyclone blade, and the width of the cyclone blade is determined by values of $10 \mathrm{~mm}, 20 \mathrm{~mm}$ and $30 \mathrm{~mm}$. It is using cyclone blade surface area $810 \mathrm{~mm} 2$ (Cyclone 1), $1620 \mathrm{~mm} 2$ (Cyclone 2), and $2430 \mathrm{~mm} 2$ (Cyclone 3). Then the cyclone is placed before the intake manifold precisely on the throttle valve, more clearly as in the sketch below:

\section{RESULTS AND DISCUSSIONS}

The research data obtained data on engine performance power, torque, and exhaust emissions.

\subsection{Power}

Power performance test results can be seen in Figure 4.

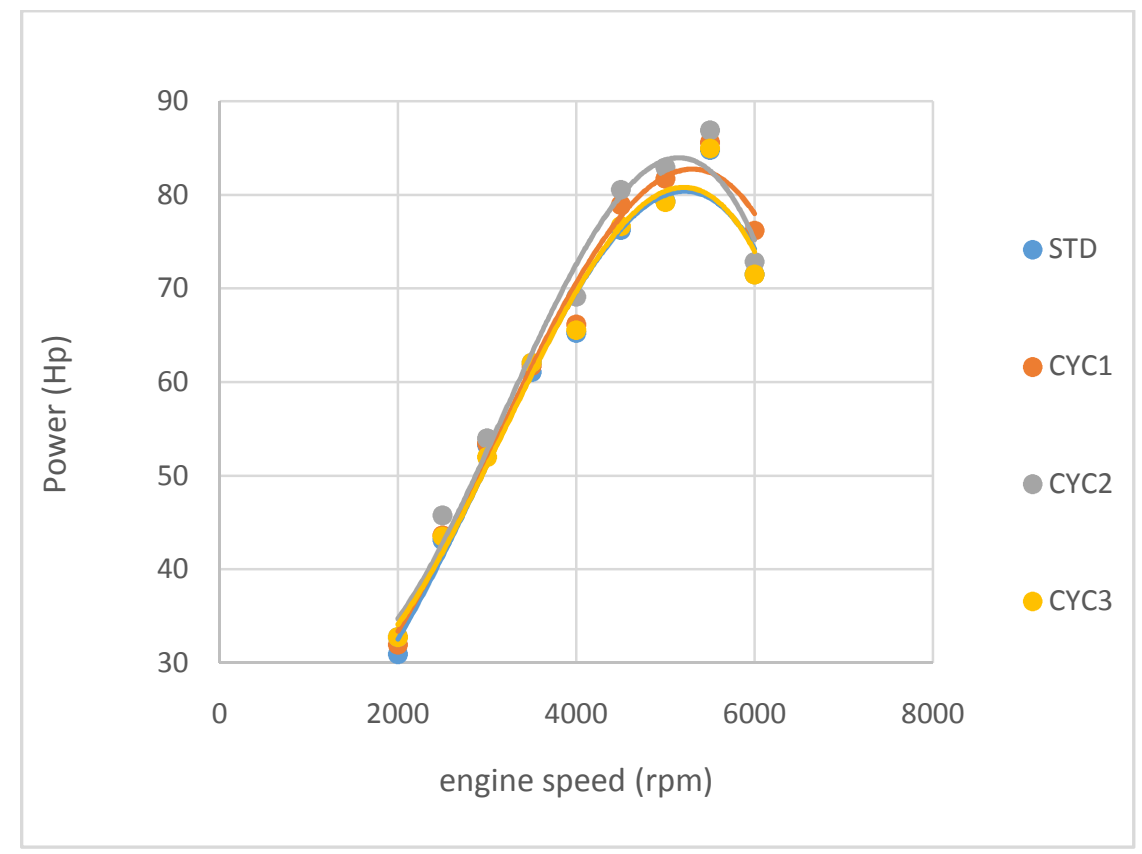

Figure 4: Relationship between engine speed and power

Figure 4. shows a significant increase in power with an increase in engine speed. The addition of cyclone surface area also increases energy. It is seen in the surface area of the blade $1620 \mathrm{~mm} 2$ at $5500 \mathrm{rpm}$ rotation. It happens because the drag coefficient at $1620 \mathrm{~mm} 2$ cyclone blade width produces good swirling flow, and can optimize the combustion process with a uniform flow pattern. Thus smoothing the air grains and fuel and breaking the vortex of fuel flow. While the motion of the oxidizing fluid influences the increase in power, if the burned fluid is swirling and causes swirling, the 
combustion velocity that occurs is higher. The use of cyclones only affects the high speed when high engine speed occurs inertia in the valve spring so that the accuracy of opening and closing the valve is reduced. Improper opening and closing of valves at high speeds result in decreased power. At the same time, cyclone with a surface area of $810 \mathrm{~mm} 2$ blade does not occur swirling flow so that the power generated is also low. Cyclone with a surface area of $2430 \mathrm{~mm} 2$ blade has a coefficient of friction in the flow of air and fuel is significant, so that the air-fuel flow is obstructed.

\subsection{Torsi}

Test results show that engine performance torque can be seen in figure 2 .

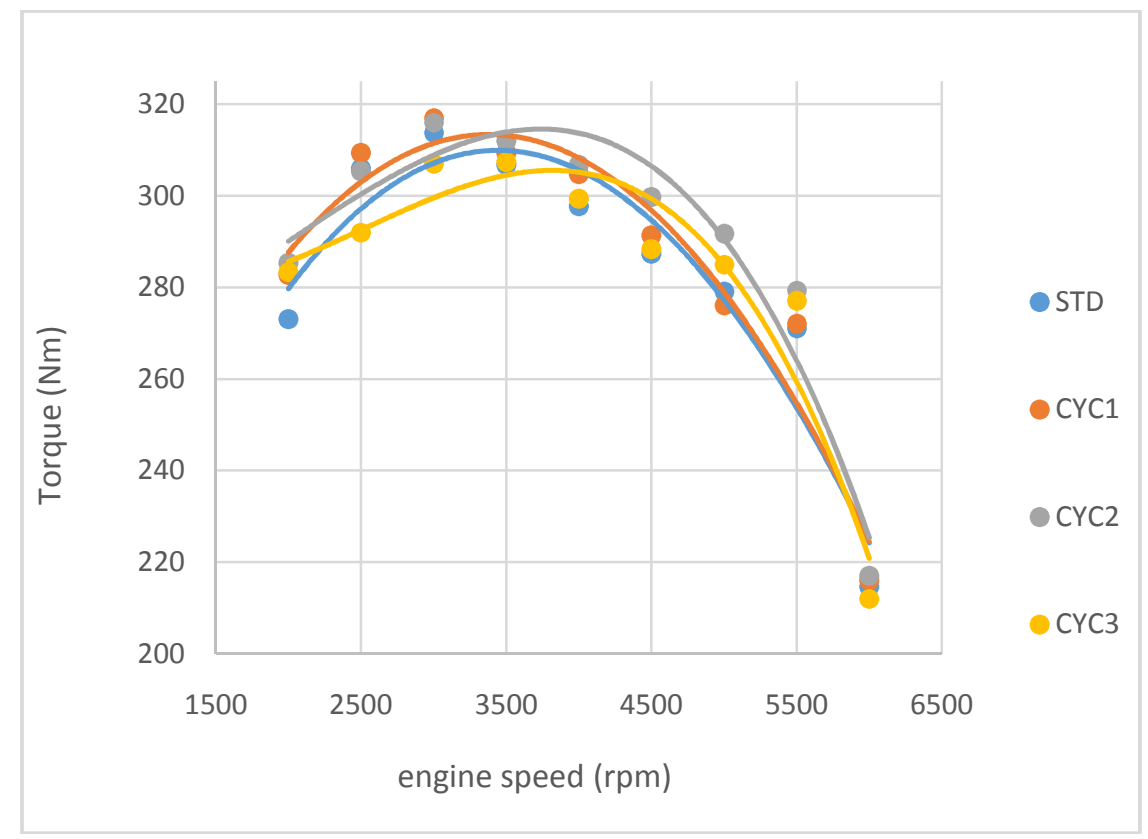

Figure 5: The relationship between engine speed and torque

Figure 5. shows the increase in torque at an initial rotation of $2000 \mathrm{rpm}$ to $3000 \mathrm{rpm}$, then decreases to $6000 \mathrm{rpm}$. It is due to the airflow and fuel are not obstructed, but less homogeneous. when it reaches a rotation of 3500 to $6000 \mathrm{rpm}$ the torque produced decreases. While the cyclone with a blade surface area of $1620 \mathrm{~mm} 2$ when the engine speed reaches $3500 \mathrm{rpm}$, the torque is high, and the airflow and fuel are more swirling so that during the compression process, the resulting pressure is high. For cyclone with blade surface area of $2430 \mathrm{~mm} 2$, the torque produced is still lower than that of a cyclone with blade surface area of $810 \mathrm{~mm} 2$ and $1620 \mathrm{~mm} 2$. It is because of the higher the surface area of the blade, the greater the resistance of airflow and fuel entering the combustion chamber. It results in low torque produced. Torque will decrease along with high engine speed. Torque starts to decrease when turning $3500 \mathrm{rpm}$. The combustion of the mixture of fuel and air produces impulsive force. The impulsive force of the motor burns small when the engine torque is small, and the impulsive force of the vehicle is high when the engine torque is high. At engine speeds that are too high, the volume of a mixture of air and fuel tends to be small. It relates to the degree of cylinder filling that is not perfect at high rotations. Suction valves and exhaust valves tend to be floating, unable to close entirely due to a short time. The decrease in torque is caused by an increase in the friction coefficient of air-fuel flow. 


\subsection{Intake Manifold Pressure}

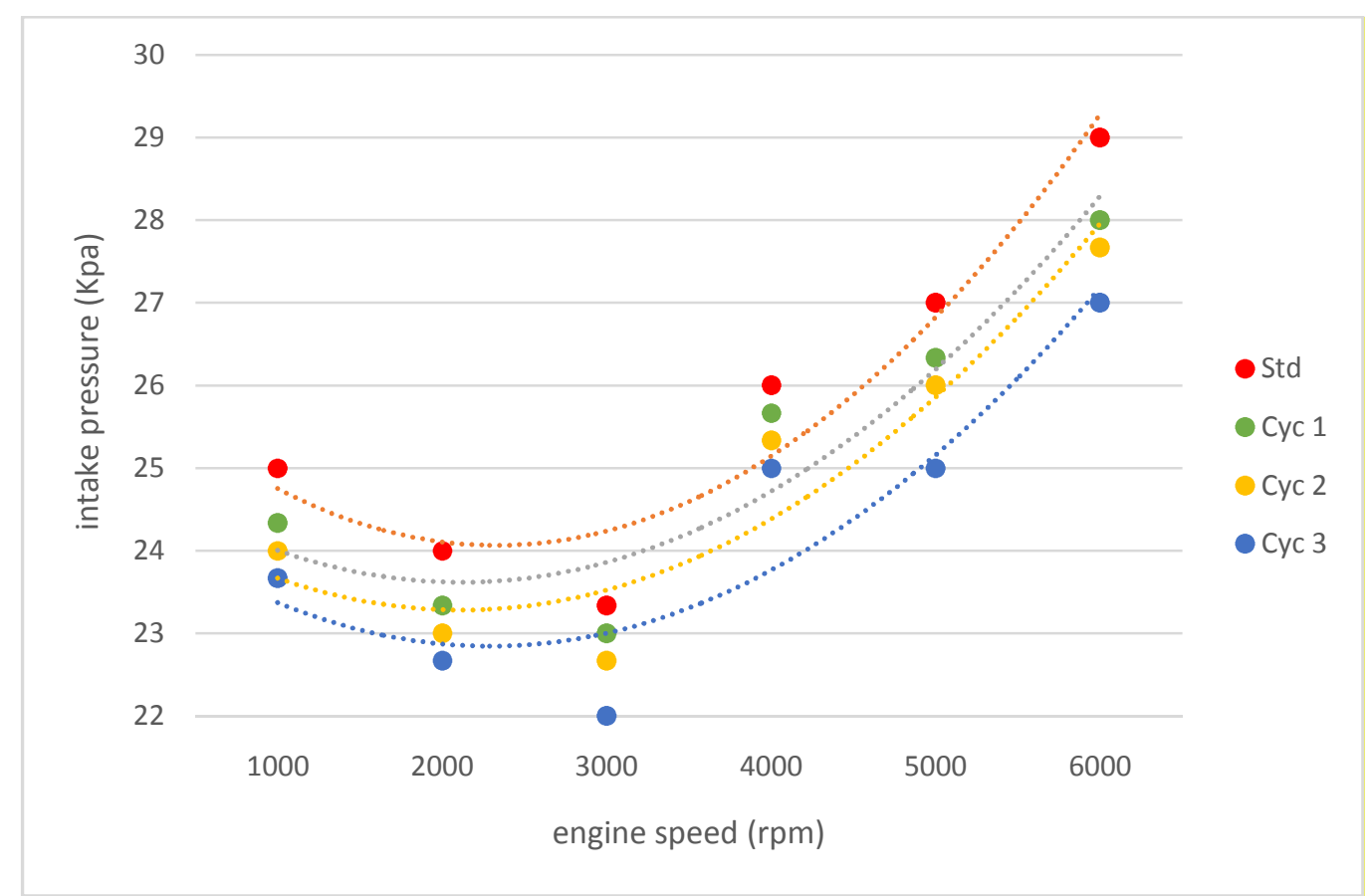

Figure 6: The relationship between Engine Speed Against Intake Manifold Pressure

Figure 6. shows variations in engine speed affecting the intake manifold pressure conditions. At $1000 \mathrm{rpm}$ rotation, the average condition shows intake pressure at $24.3 \mathrm{Kpa}$. Whereas at engine speed $2000 \mathrm{rpm}$ and $300 \mathrm{rpm}$ shows the intake manifold pressure is low, this is due to the higher engine vacuum, the more air demand so that intake pressure decreases. At $4000 \mathrm{rpm}$ rotation condition of intake pressure rises to an average of $25.5 \mathrm{Kpa}$, this is due to the condition of the engine that requires quite a lot of air, but the movement of the suction valve is faster so that the air entering the combustion chamber is blocked and causes an increase in the amount of air in intake chamber. At 5000 rpm engine speed, the intake manifold pressure again increases to an average of $26.1 \mathrm{Kpa}$. It happens because of the faster engine speed in line with the rapid movement of the intake and exhaust valves. When the throttle is wide open, but the intake valve's movement is fast, the incoming air becomes not optimal so that the air trapped in the intake manifold increases, and the pressure rises. 


\subsection{HC Exhaust Emissions}

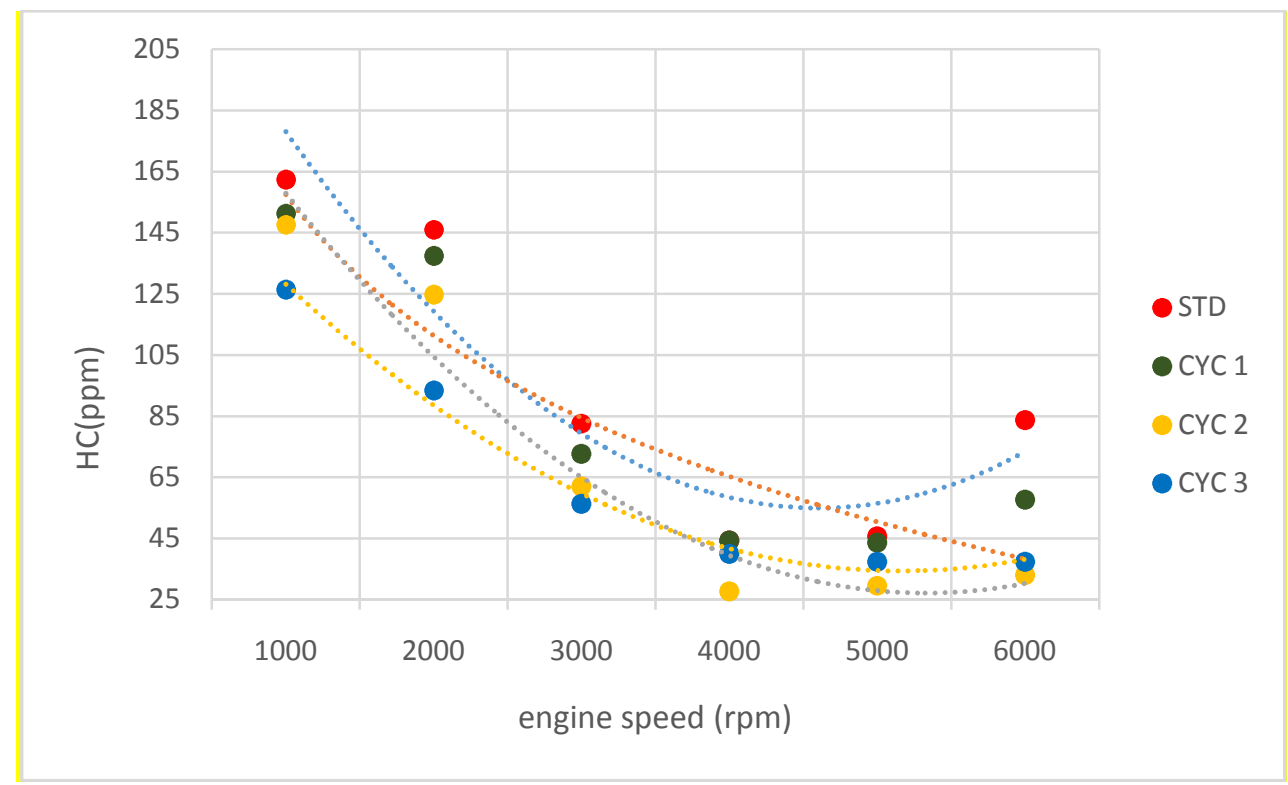

Figure 7: The relationship between of Engine Speed against HC

Figure 7 shows that the engine speed affects the $\mathrm{HC}$ exhaust emissions. It is due to the high engine speed, which also shortens the overlapping time. $4000 \mathrm{rpm}$ engine speed HC content decreased to an average of 39.0. It is due to the movement of the suction valve, and the exhaust is getting shorter. It so that less fuel is wasted due to overlapping. At 5000 rpm engine speed HC content decreased again, this is due to faster overlapping movements, but the fuel is getting richer so that the power for combustion is sufficient. At $6000 \mathrm{rpm}$, the $\mathrm{HC}$ content increases. It is due to the overlapping process so that the results decrease because the overlapping time is getting shorter. The higher the engine speed, the mixture of air, and fuel richer. The mixture is to meet the power needed by the engine. The combustion of the air-rich fuel mixture in the combustion chamber causes residual fuel. It causes high $\mathrm{HC}$ content.

\subsection{CO Exhaust Emissions}

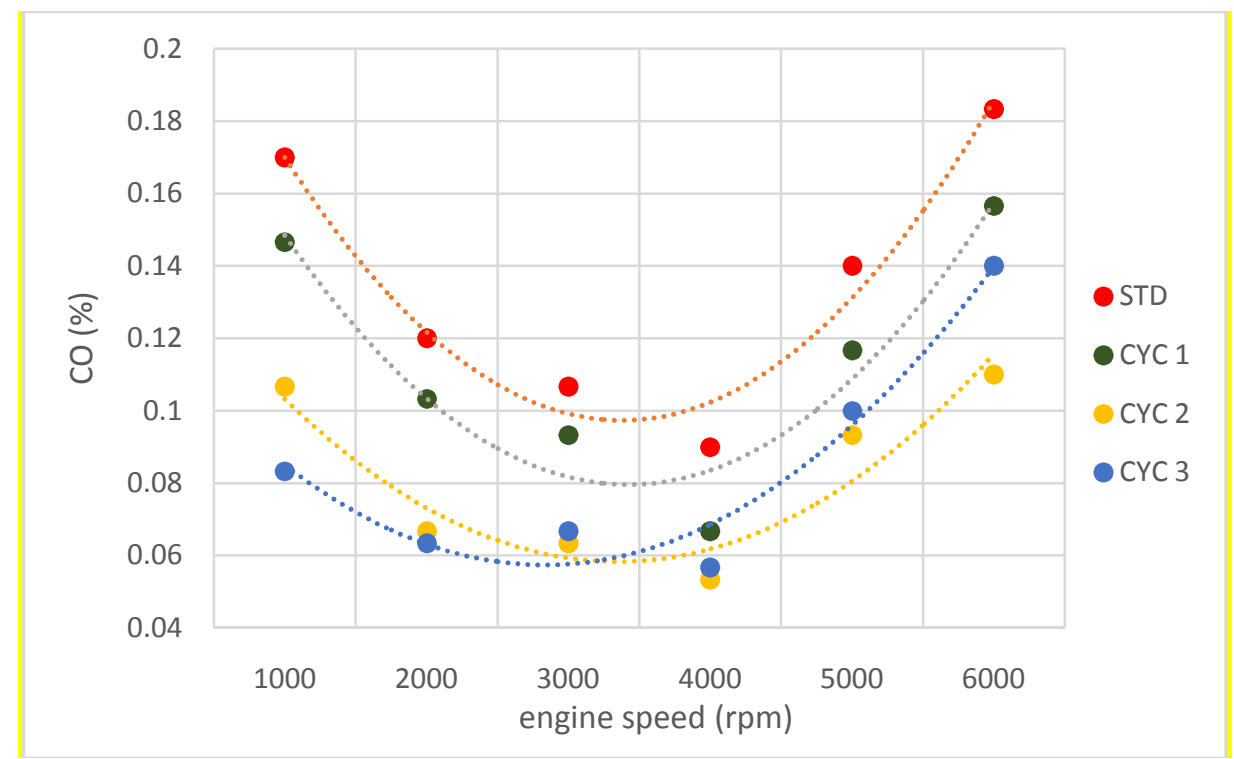

Figure 8: The relationship between of Engine Speed against CO 
Figure 8. shows the downward trend from low speed to $4000 \mathrm{rpm}$, and then the trend changes up when the engine speed is more than $4000 \mathrm{rpm}$. Engine speed has a significant effect on the content of CO (Carbon Monoxide) exhaust emissions. At $1000 \mathrm{rpm}$, engine speed CO exhaust emissions have an average of $0.11 \%$. It happens because the combustion is less than perfect. It is due to a slightly rich fuel mixture to maintain the idling process. At 2000 rpm engine speed, the $\mathrm{CO}$ exhaust emission content decreased to an average of $0.08 \%$. It happens because the fuel mixture is thinner, so the fuel can burn more completely. At an engine speed of $3000 \mathrm{rpm}$, the $\mathrm{CO}$ exhaust emission content decreases again to an average of 0.074 . Here, the intake valve movement has begun to be advanced by the vehicle injection system, so that more air enters the combustion chamber. It causes the mixture of air and fuel to be thin so that the CO exhaust emission content decreases. At $4000 \mathrm{rpm}$, the $\mathrm{CO}$ exhaust emission content decreased again to an average of $0.058 \%$. It can occur because the mixture of air and fuel is getting closer to AFR 14.7. At 5000 rpm engine speed, the CO exhaust emission content starts to increase sharply. It happens because the air mixture is starting to be a little bit rich, and the short time of the combustion process causes more $\mathrm{CO}$ than the 4000 rpm engine speed.

The use of cyclones can reduce $\mathrm{CO}$ exhaust emissions. It is because cyclones can change the flow of air inlet through the throttle into turbulent so that the mixture of fuel and air becomes more homogeneous than the other. So that combustion will be perfect, and exhaust emissions become more environmentally friendly. Based on Figure 4, the most efficient cyclone in improving the combustion process is a cyclone with a blade width of $2 \mathrm{~cm}$ because the cyclone is capable of producing the most stable $\mathrm{CO}$ exhaust emissions. However, the cyclone with a blade width of $3 \mathrm{~cm}$ is more swirling. Less air enters the engine and reduces combustion quality.

\section{CONCLUSIONS}

Based on the research, the following conclusions can be drawn:

- There is an effect when adding a cyclone with a blade surface area of $1620 \mathrm{~mm} 2 \mathrm{of} 87 \mathrm{hp}$ at $5500 \mathrm{rpm}$ and the resulting torque value of $312 \mathrm{Nm}$ at $3500 \mathrm{rpm}$ with an average effective pressure of $1049 \mathrm{kPa}$ or equivalent to 10 bar at engine speed $2500 \mathrm{rpm}$. It happens because the power and torque produced are good with good average effective pressure. Able to produce more homogeneous airflow and fuel and accelerate the combustion process, so that engine performance increases.

- On the power generated, the use of a cyclone only affects high engine speed because the air and fuel flow produced is higher than when the engine speed is low. However, when the engine speed is too high, the power produced is low due to the possibility of the intake valve closing before the air and fuel flow into the cylinder. In the torque and average effective pressure data that is generated along with the high engine speed, the resulting value is also low because the friction coefficient of the piston movement is large and the degree of filling of the cylinder is decreasing, resulting in low torque and the resulting average sufficient pressure.

\section{REFERENCES}

1. National Research Council, Environmental transport and exposure pathways of substances emitted from incineration facilities. 2000.

2. B. Sagot, A. Forthomme, L. A. A. Yahia, and G. De La Bourdonnaye, "Experimental study of cyclone performance for blow-by gas cleaning applications,” J. Aerosol Sci., vol. 110, no. May, pp. 53-69, 2017, doi: 10.1016/j.jaerosci.2017.05.009.

3. A. Surjosatyo, A. Respati, H. Dafiqurrohman, and Muammar, "Analysis of the Influence of Vortexbinder Dimension on 
Cyclone Separator Performance in Biomass Gasification System,” Procedia Eng., vol. 170, pp. 154-161, 2017, doi: 10.1016/j.proeng.2017.03.036.

4. J. Chen, B. Yang, Z. A. Jiang, and Y. Wang, "Effect of External Cyclone Diameter on Performance of a Two-Stage Cyclone Separator," ACS Omega, vol. 4, no. 8, pp. 13603-13616, 2019, doi: 10.1021/acsomega.9b02216.

5. J. Chen, Z. A. Jiang, and J. Chen, "Effect of Inlet Air Volumetric Flow Rate on the Performance of a Two-Stage Cyclone Separator,” ACS Omega, vol. 3, no. 10, pp. 13219-13226, 2018, doi: 10.1021/acsomega.8b02043.

6. F. Ficici, V. Ari, and M. Kapsiz, "The effects of vortex finder on the pressure drop in cyclone separators," no. June 2014, 2010.

7. M. R. O. Rayyan, "ANALYSIS OF THE EFFECT OF TWO TURBO CYCLONES WITH SIX BLADES TOWARDS THE PERFORMANCE OF A 4-STROKE MECHANICAL ENGINEERING DEPARTMENT FACULTY OF ENGINEERING,” 2020.

8. M. A. Jemni and M. S. Abid, "Intake manifold design effect on air fuel mixing and flow for an LPG heavy duty engine," no. January, 2012.

9. "The effects of injection pressure on swirl and flow pattern in diesel combustion."

10. T. Reports, “Experimental study of turbulent flows through pipe bends Athanasia Kalpakli," no. April, 2012.

11. A. Nordin, ON THE CHEMISTRY OF COMBUSTION AND GASIFICATION OF BIOMASS FUELS, PEAT AND WASTE; ENVIRONMENTAL ASPECTS by. 1993.

12. J. L. Lumley, "Flow in the Cylinder," Engines, pp. 134-184, 2012, doi: 10.1017/cbo9781139175135.007.

13. R. K. Tyagi, S. K. Sharma, A. Chandra, S. Maheshwari, and P. Goyal, "IMPROVED INTAKE MANIFOLD DESIGN FOR I . C . ENGINE EMISSION CONTROL,” vol. 10, no. 9, pp. 1188-1202, 2015.

14. A. Tamburrino, "Condition for the Incipient Motion of Non-Cohesive Particles Due to Laminar Flows of Power-Law Fluids in Closed Conduits," 2020.

15. Sunaryo, A. Irfan, M. Setiyo, and N. Amin, "Design and simulation of mixer insulators to improve turbulence in intake manifold,” J. Phys. Conf. Ser., vol. 1517, no. 1, pp. 1-6, 2020, doi: 10.1088/1742-6596/1517/1/012009.

16. S. Adiloğlu et al., "We are IntechOpen, the world's leading publisher of Open Access books Built by scientists, for scientists TOP $1 \%$," Intech, vol. i, no. tourism, p. 13, 2012, doi: 10.1016/j.colsurfa.2011.12.014.

17. LBNL, "Improving Fan System Performance: A Sourcebook for Industry," U.S. Dep. Energy, pp. 1-92, 2003, doi: 10.1186/s12864-018-4501-8.

18. F. CHEN and H. LIU, "Particle image velocimetry for combustion measurements: Applications and developments," Chinese J. Aeronaut., vol. 31, no. 7, pp. 1407-1427, 2018, doi: 10.1016/j.cja.2018.05.010.

19. S. Marthinussen, M. Thesis, and P. Technology, "The Effect of Fluid Viscosity on Hydrocyclone Performance," no. July, 2011.

20. A. Olusegun et al., "We are IntechOpen, the world's leading publisher of Open Access books Built by scientists, for scientists TOP $1 \%$," Intech, vol. i, no. tourism, p. 38, 2012, doi: 10.1016/j.colsurfa.2011.12.014.

21. F. Ficici, A. Vedat, and M. Kapsiz, "The effects of vortex finder on the pressure drop in cyclone separators," Int. J. Phys. Sci., vol. 5, no. 6, pp. 804-813, 2010.

22. M. Taufik Fajar Nugroho, "Effect of Swirl Generator Intake Manifold on Engine Performance using Ethanol/Gasoline Blend," Asian J. Appl. Sci., vol. 4, no. 6, pp. 1342-1349, 2016. 
23. Z. Xiong, Z. Ji, and X. Wu, "Investigation on the separation performance of a multicyclone separator for natural gas purification," Aerosol Air Qual. Res., vol. 14, no. 3, pp. 1055-1065, 2014, doi: 10.4209/aaqr.2013.09.0298.

24. T. Golden, B. Reed, and A. Das, “Handbook of Biomass Downdraft Gasifier Engine Systems,” SERI . U.S. Dep. Energy, no. March, p. 148, 1988, doi: 10.2172/5206099.

25. M. S. K. Tony, S. Utomo, and L. Belakang, "Simulasi Efek Turbo Cyclone Terhadap Karakteristik Aliran Udara Pada Saluran Udara Suatu Motor Bakar Menggunakan Computational Fluid Dynamics,” Simulasi Efek Turbo Cyclone Terhadap Karakteristik Aliran Udar. Pada Saluran Udar. Suatu Mot. Bakar Menggunakan Comput. Fluid Dyn., vol. 8, no. 2, pp. 30-36, 2006, doi: 10.14710/rotasi.8.2.30-36.

26. P. . Bunyawanichakul, "Development of a Cyclone Rice Dryer,” no. September, 2006.

27. D. L. Siebers, R. G. Schwind, and R. J. Moffat, "Experimental Mixed Convection From a Large, Vertical Plate in a Horizontal Flow.," Heat Transf. Proc. Int. Heat Transf. Conf., pp. 477-482, 1982, doi: 10.1615/ihtc7.2940.

28. Z. Barbouchi and J. Bessrour, "Turbulence study in the internal combustion engine," vol. 1, no. 9, pp. 194-202, 2009.

29. S. H. Abidi and M. M. Hasan, "Effect due to Variation in Bend Angles of Intake Manifold on Turbulent Kinetic Energy for Diesel Engine,” Int. J. Innov. Technol. Explor. Eng., vol. 9, no. 5, pp. 1979-1982, 2020, doi: 10.35940/ijitee.e2973.039520.

30. J. Energi et al., “TERHADAP KINERJA DAN SUHU KERJA MOTOR,” vol. 03, no. 01, pp. 27-34, 2020.

31. R. Alat, B. Kayu, S. Putaran, D. Pengaturan, T. Motor, and I. M. Parsa, “Jurnal Ilmiah Teknologi FST Undana Vol. 14, No. 1, Edisi Mei 2020 2020,”vol. 14, no. 1, pp. 1-9, 2020. 